\title{
개발협력분야의 메타평가 소개와 KOICA평가에 대한 시사점
}

박 숙 현 KOICA평가실 대리

\section{목차}

I. 들어가며

II. 메타평가의 개념

III. 메타평가의 활용 및 사례

IV. 개발협력분야에서의 메타평가

$\mathrm{V}$. KOICA의 평가분야 시사점

VI. 메타평가 활용의 고려사항 및 향후 연구과제 제언

\section{I. 들어가며}

2010년 11월 제 7차 개발협력위원회에서 의결된 「ODA선진화 방안 에서는 주요 사항으로 ODA의 평가를 다루고 있다 ${ }^{1)}$. 특히 다원화된 국내 원조 추진체계로 인한 재원을 총체적으로 관리하고 효과성 을 제고하기 위하여, 통합평가시스템을 활용하겠다는 계획을 포함하고 있다. 개발협력분야 평가의 중 요성과 필요성이 증대되는 이러한 시점에, $\mathrm{ODA}$ 주요 평가분야 담당기관 중 하나인 $\mathrm{KOICA}$ 의 평가 분야 역할과 기능이 더욱 중요해질 것으로 기대된다. 따라서 $\mathrm{KOICA}$ 의 평가품질(Quality)과 신뢰성 확보를 위한 방안으로 메타평가를 소개하고자 하며, 특히 개발협력분야에서의 메타평가 쓰임과 시사 점에 대해서 간략히 논의하고자 한다. 본 글의 목적은 아래와 같이 요약될 수 있다.

- 메타평가를 소개하고, 개발협력분야의 활용 개념을 공유한다.

- $\mathrm{KOICA}$ 와 국내개발협력분야 메타평가 필요성을 제기한다.

- 향후 적용방향 및 고려사항들을 점검한다.

1) 국제개발협력위원회(관계부처 합동), 2010, 국제개발협력 선진화 방안 


\section{II. 메타평가의 개념}

\section{1. 메타평가의 정의}

메타평가(Metaevaluation)란 “평가에 대한 평가(Evaluation of Evaluation)”로 잘 알려져 있으 며 보통 “상위평가" 또는 "제 2 차 평가”라고도 하며, 우리나라의 경우는 2006년 제정된 정부업무평가 기본법에 의거 “재평가"라고도 한다2). "Meta"는 그리스어의 접두사로 “ 함께” 또는" 후에” 라는 뜻을 포함하고 있으며 “Evaluation”과 함께 쓰이면서 특정분야의 본질이나 가정 및 구조 등을 고찰 하는 것을 목적으로 하는 학문명과 같은 쓰임으로 사용될 수 있다(김병철, 2009, Agnes, 2000재인 용). 평가자체의 기본기능이 의도한 목표대로 활동이나 사업이 진행되었는지, 효율적으로 달성되었는 지, 유사활동을 위한 교훈이 무엇인지를 체계적이고 객관적으로 검증하는 과정이라면 $(\mathrm{OECD} / \mathrm{DAC}$ 평가정의), 메타평가는 아래 〈그림1〉과 같이 과연 평가가 의도한 평가목적을 잘 달성했는지, 체계적 이고 객관적으로 평가를 수행 했는지, 결과가 과연 유용한 것인지 등을 다시 점검하는 과정으로 이해 할 수 있을 것이다. 따라서 평가 자체에 대한 목적과 의도, 사용되는 방법이 다양하듯이, 메타평가 자 체의 목적, 의도, 그에 따른 구분 등이 여러 가지로 분류될 수 있다. 하지만 이러한 분류에 앞서 가장 먼저 생각해 보아야 할 점이 바로 “왜?” 평가에 대한 평가를 실시하게 되었는지 이다.

\section{〈그림 1〉메타평가의 기본개념3)}

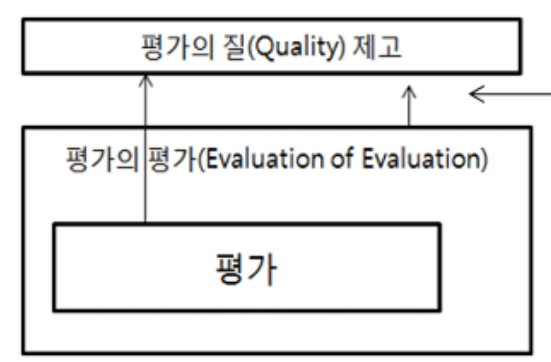

\section{메타평가의 기준}

\section{2. 메타평가의 목적}

메타평가를 실시하게 되는 주된 요인은 바로 “평가의 품질”확보를 위함이다.(류영아, 2007, Mark and Henry 2004, ALNAP Review 2003 외 다수). 메타평가를 통해 얻고자하는 바가 무엇인지에 따라, 메타평가 기준과 범위를 설정하게 되고, 이에 따라 최종적으로는 평가품질 제고의 목적을 달성

2) 류영아(2009), 한국행정학보 제43권 제 2호

3) 김순남(2006), The Journal of Educational Administration, <그림1>을 저자 재구성 
하게 되는 것이다. 평가를 통해 생산된 많은 제언과 결과들이 현실에서 적용되거나 받아들여지지 않 은 사례가 발생되기 시작하면서, 행정학 및 공공행정책 분야에서 메타평가의 필요성과 연구가 활발히 이루어지기 시작하였다(김태훈, 2006). 즉 평가자체의 목적을 달성할 수 없다고 판단될 때, 평가에 대한 평가를 실시하여 그 원인을 규명토록 하는 목적으로 메타평가를 실시하게 되었다. 또한 평가결 과의 저조한 활용은 평가결과의 타당성, 평가방법의 신뢰성, 평가기준의 적합성등으로 연계되었으며 종합적인 평가시스템의 문제에서 기인하는 경우도 배제할 수 없게 되었다. 이러한 경우는 평가 절차, 기준, 평가 시스템에 대한 전반적인 점검을 목적으로 메타평가가 이루어져 왔다. 좁은 의미의 목적으 로는, 평가관련한 문제가 없는 경우라 할지라도, 평가기법의 일환으로써 여러 평가건의 결론을 취합 하여 하나의 종합평가결론을 재 도출하는 목적으로도 메타평가가 실시되기도 하였다. 특히 기관 및 조직평가를 실시할 때, 상위기관 및 위원회 등이 시간 및 비용을 절약하면서 총체적으로 기관의 활동 을 평가하고자 자체평가의 결과를 바탕으로 메타평가를 많이 활용해왔다.

\section{3. 메타평가의 기준 및 방법}

메타평가의 목적에 따라 적용하는 평가항목과 기준은 차이가 나지만, 일반적으로 (1)평가환경 (Environment), (2)평가투입(Input), (3)평가수행(Process), (4)평가활용(Utilization)으로 나누어 분 류할 수 있다. 본 글에서는 국 - 내외의 각 메타평가사례를 바탕으로 메타평가의 모형을 표준화한 최 근연구(김병철, 2009)를 준용하여, 메타평가의 구성요소를 설명하도록 하겠단)

먼저 평가환경은 평가근거, 평가목적, 평가주기를 항목으로 포함하고 있는데, 이는 일부 평가기획 과정의 평가 설계 요소와, 평가수행환경의 법적, 제도적 기반을 점검하기 위함이다. 즉, 평가의 법적 근거가 명료하게 구성되어 있는지, 시행지침, 가이드라인이 합리적으로 규정되어 있는지가 이에 해당 한다. 또한 평가목적 부분에서는 이해관계자들이 평가를 쉽게 이해할 수 있도록 평가목적이 명료한 지, 성과향상 등 조직의 발전에 부합하도록 합리적으로 제시되어 있는지를 포함한다. 평가주기는 피 평가자가 피로감을 느낄 정도 인지, 또는 평가의 목적을 달성할만한 시기를 합리적으로 선별하였는지 를 포함하고 있다. 평가투입요소는 평가자의 역량, 구성, 전문성 항목과 함께, 평가자료의 질적 - 양 적 적절성, 평가시간의 충분성 등을 포함하고 있다. 평가수행 부분은 평가설계(Design)와 가장 밀접 하게 연관이 되는 평가항목, 지표 등을 포함한 평가내용, 평가절차, 평가방법, 평가보고서 구성 및 내 용을 포함하고 있다. 평가의 활용부분은 평가환류(Feedback)체계를 종합적으로 판단할 수 있는 근거

4) 비록 위의 연구에서는 표준화된 메타평가 모형의 틀은 국내 연구기관 평가에 대한 분석기준을 엄격히 선별하여 만든 것 이긴 하지만, 메타평가의 해외 사례연구와 국내의 광범위한 메타평가관련 연구를 바탕으로 공통요소들을 선별했다는 점 에서 일반적인 소개에 모델사례로 활용해도 무리가 없을것으로 판단되어 본 글에서 활용토록 한다. 
가 되는 항목들로 구성되어져 있는데, 먼저 평가결과 확정 절차 및 등급산정의 합리성을 포함하는 평 가결과 확정, 결과보고체계 및 배포의 적절성, 공개범위 등을 포함하는 평가결과보고(Reporting)부분, 평가결과의 활용측면, 평가시스템 개선활동 측면 등을 포함하고 있다.

〈표 1〉김병철(2009), 메타평가론, 메타평가 모형의 설계와 적용, 한국학술정보, p186

\begin{tabular}{|c|c|c|}
\hline 영역 & 평가항목 & 평가지표 \\
\hline \multirow{3}{*}{$\begin{array}{l}\text { 평가 } \\
\text { 환경 }\end{array}$} & 평가근거 & 평가법적 근거의 명료성/ 평가관련 법규내용의 합리성 \\
\hline & 평가목적 & 평가 목적의 명료성/ 평가목적의 합리성 \\
\hline & 평가주기 & 평가주기의 합리성/ 평가지표별 평가주기의 신축성 \\
\hline \multirow{3}{*}{$\begin{array}{l}\text { 평가 } \\
\text { 투입 }\end{array}$} & 평가역량 & 평가추진체계의 기능적 적정성/평가단 구성의 적절성/ 평가이해관계자 파악의 적절성 \\
\hline & 평가자료 & 평가자료의 양적,질적 적절성 \\
\hline & 평가시간 & 서면평가 및 실사평가 시간의 충분성/ 평가편람 배포시기의 적절성 \\
\hline \multirow{4}{*}{$\begin{array}{l}\text { 평가 } \\
\text { 수행 }\end{array}$} & 평가내용 & $\begin{array}{l}\text { 평가항목 및 지표 구성의 적절성/ 평가항목의 연차별 일관성 유지정도/ 평가배점의 선 } \\
\text { 택의 신축성 }\end{array}$ \\
\hline & 평가절차 & 평가절차의 합리성/ 평가기준 설명의 적절성/평가자와 대상자간 의사소통의 충분성 \\
\hline & 평가방법 & 평가기준 판단 근거의 명료성/평가방법의 적절성 \\
\hline & 평가보고서 & 평가보고서 구성 및 내용의 합리성/평가보고서 결론 및 제언의 적정성 \\
\hline \multirow{4}{*}{$\begin{array}{l}\text { 평가 } \\
\text { 활용 }\end{array}$} & 평가결과 확정 & 평가결과 확정 절차의 적절성/표평가등급 산정의 합리성 \\
\hline & 평가결과 보고 & $\begin{array}{l}\text { 평가결과 보고체계의 명료성/평가보고서 배포의 적절성/평가결과 공개법위 및 수준의 } \\
\text { 적절성 }\end{array}$ \\
\hline & 평가결과 활용 & $\begin{array}{l}\text { 평가활용에 대한 법,제도적 근거의 명료성/평가자 측면의 평가결과 활용의 충분성/평가 } \\
\text { 대상자 측면에서 평가결과 활용의 충분성 }\end{array}$ \\
\hline & 평가시스템 개선 & 평가시스템에 대한 평가 및 개선활동의 적절성 \\
\hline
\end{tabular}

메타평가의 방법론 측면에서는 주로 체크리스트 형식의 평가항목에 따라 그 결과를 등급화 또는 가중치를 부여하는 방식으로 주로 쓰이며, 리커드 척도를 이용하여 계량화하는 경우도 다수 발견된 다. 또한 메타평가가 기존에 이루어진 평가의 평가라는 점을 생각해볼 때, 기존평가자들의 의견을 인 터뷰하거나 설문하는 방식의 조사방법론도 함께 쓰이면서 결과는 계량화하여 나타내는 경우가 많다.

\section{III. 메타평가의 활용 및 사례}

\section{1. 국외의 메타평가 사례}

메타평가 연구를 활발히 추진한 국외 학자로는 대표적으로 Daniel L. Stufflebeam, Cook\& Gruder (1978), Larson\& Berliner(1983), Chelimsky(1985)등이 있다. 초창기 연구는 1940년대 정책의 기획기능 및 평가기능이 강조되던 시기와 함께 메타평가의 범주 및 주요대상, 정의, 개념적 
측면에 중점을 두고 연구가 추진되었다. Daniel L. Stufflebeam의 경우는, 메타평가를 평가활동 의 길잡이 및 가이드라인(to guide the evaluation)으으로 그 성격을 정의하고, 메타평가를 평가시 스템 점검의 유용한 도구로 활용하기를 주장하였다. Chelimsky(1985)는 메타평가를 그간 평가결 과의 종합과 재분석 측면에서 유용성을 강조 하였다. 이렇듯 메타평가는 평가결과를 정책적으로 반 영하고, 정부사업 및 정책단위에 활용하기 위한 것으로 연구되고 발전되어져 왔는데, 국외 메타평 가사례는 류영아의 “외국의 메타평가 추진실태” 연구에서 미국, 영국, 호주 사례를 살펴볼 수 있 다. 미국의 경우는, 주정부에서 제시한 에너지사업(WAP)의 성과를 연방정부 차원에서 메타평가를 통해 확인하는 목적으로 이루어진 사례이며, 다년간(1998 2002)의 평가결과를 메타분석함으로써 사업의 효과성을 검증한 경우이다. 특히, 주정부 평가가 발견하지 못했던 부분을 관련주들의 메타 평가를 통해 발견하기도 하였다. 영국의 경우는 지방정부의 개혁의제와 연관된 정책들의 효용을 부 총리실 차원에서 점검하는 목적에서 메타평가를 실시하였으며, 메타평가 기준을 지방정부의 책임성 확보 측면에 초점을 두고 다년간(2002 2008)의 사례연구와 메타분석을 실시하였다. 호주의 경우 는, 개발 $\mathrm{NGO}$ 협력프로그램의 효과성을 평가하기위하여, 호주개발협력청(AusAID)에서 각 지원받 은 $\mathrm{NGO}$ 의 평가보고서를 메타평가하고 평가보고서의 질과 활동결과를 점검한 사례이다. 특히 평가 자체가 책임성과 지속적인 향상간의 균형을 제공하였는지 여부, 논리적이고 확실한 방법론을 활용 하였는지 여부, 평가로부터 습득한 지식들과 평가의 유용성등의 기준을 가지고 메타평가분석을 $\mathrm{NGO}$ 평가분석에 활용하였다.

〈표 2〉외국의 메타평가 제도

\begin{tabular}{c|l|l|l}
\hline 국가 & \multicolumn{1}{|c|}{ 메타평가 대상 } & \multicolumn{1}{|c}{ 메타평가 과정 } & \multicolumn{1}{c}{ 특징 } \\
\hline \multirow{2}{*}{ 미국 } & $\begin{array}{l}\text { WAP 평가에 대한 } \\
\text { 메타평가 }\end{array}$ & $\begin{array}{l}\text { - 주정부에서 WAP에 대해 평가 } \\
- \text { 평가 결과를 수집하여 에너지국(DOE)에서 } \\
\text { 메타평가 }\end{array}$ & $\begin{array}{l}- \text { 예산에 대한 관여 } \\
- \text { 미래 예측 수단 }\end{array}$ \\
\hline 영국 & $\begin{array}{l}\text { LGMA 평가에 대한 } \\
\text { 메타평가 }\end{array}$ & $\begin{array}{l}- \text { LGMA에 포함된 정책을 각 정책별로 평가 } \\
- \text { 부총리실(ODPM)에서 메타평가 }\end{array}$ & $\begin{array}{l}\text { - 전반적인 상위평가 } \\
- \text { 설문조사도 실시 }\end{array}$ \\
\hline 호주 & $\begin{array}{l}\text { NGO 평가에 대한 } \\
\text { 메타평가 }\end{array}$ & $\begin{array}{l}\text { 가개의 각 지역 NGO의 활동을 NGO들이 } \\
\text { 자체평가 } \\
- \text { 국제개발청에서 메타평가 }\end{array}$ & $\begin{array}{l}\text { 프로그램 관리를 위해 } \\
\text { 메타평가 } \\
- \text { 평가보고서 점검 }\end{array}$ \\
\hline
\end{tabular}

출처: 류영아, 외국의 메타평가 추진실태 표 4

5) Daniel L. Stufflebeam(2001), The Metaevaluation Imperative, American Journal of Evaluation 2001 22: 183 


\section{2. 국내의 메타평가 사례}

국내의 경우 메타평가를 소개하고 연구한 학자로는 오무근(1986), 김명수(1993), 이찬구(1997), 김병철(2009)등이 있다. 기존 Daniel L. Stufflebeam 등과 같은 해외 선행연구를 바탕으로 국내에 메타평가개념을 소개하고, 재정리하고, 사례연구를 하면서 메타평가의 연구는 발전하였는데, 국내에 서도 공공 행정분야에서 널리 활용되었다. 특히 국내의 경우는 2001년 '정부업무등의 평가에 관한 기 본법'제정 및 2006년 ‘정부업무평가 기본법’ 시행에 따라6) 정부자금으로 지원되는 연구, 기술 분야, 기타 재정사업, 공공기관평가 등에 평가가 의무화 되면서, 증대되는 평가를 효율적으로 관리하고 기 관자체평가의 효과성을 검증하기 위해 메타평가가 확산되게 된다. 대학평가부분(교육), 국방연구개발 사업(연구), 정부출연기관평가(기관), 기술영향평가(정책 및 행정), 복권기금사업, 지방자치단체 등 재정사업을 수행하고 있는 200 개의 기관 및 다방면에 메타평가기법이 도입되어 추진한 사례가 있다.

〈표 3〉 김병철(2009), 메타평가론, 메타평가 모형의 설계와 적용, 한국학술정보, $48 p$ 에서 편집

\begin{tabular}{|c|c|c|}
\hline 평가단위 & 연구자(시기) & 주요내용 \\
\hline 기관평가 & $\begin{array}{l}\text { 이찬구 · 강근복(1999) } \\
\text { 송형주(2002) } \\
\text { 김명수(2003) } \\
\text { 임성옥(2003) } \\
\text { 김현구 · 박희정(2003) } \\
\text { 송환빈(2004) } \\
\text { 공병천(2004) } \\
\text { 이찬구(2004) } \\
\text { 홍성걸(2004) } \\
\text { 문영세(2005) } \\
\text { 황병상 · 강근복(2005) } \\
\text { 이혜승 외(2006) } \\
\text { 김순남(2002, 2006) } \\
\text { 송희준 · 조택(2006) } \\
\text { 김태훈(2006) } \\
\text { 김용훈 · 오영균(2007) } \\
\text { 권혁인(2008) } \\
\text { 김병철(2008) }\end{array}$ & $\begin{array}{l}\text { 정부출연기관 평가제도 발전방향: 과기계 연구기관 평가사례 중심 } \\
\text { 정부출연연구기관 메타평가에 관한 연구: 공공기술연구회 중심 } \\
\text { 중앙행정기관 평가제도의 운영에 대한 비판적 검토 } \\
\text { 사회복지시설 평가에 대한 메타평가 } \\
\text { 광역자치단체 합동평가체제의 실증분석 } \\
\text { 한 · 일 공공연구기관 평가시스템의 비교 · 분석 연구 } \\
\text { 자체평가 및 상위평가 개선방안 } \\
\text { 과학기술계 연구회의 기관평가제도 발전방안: 산업기술연구회 사례 중심 } \\
\text { 과학기술부 출연기관 평가: 기관평가사례의 실증적 분석 } \\
\text { 정부업무평가에 대한 메타평가: 국방부 중심 } \\
\text { 정부출연연구기관 평가의 발전방안 논고: 기초기술연구회 중심 } \\
\text { 지방공기업 경영 및 평가제도 개선방안 연구 } \\
\text { 학교/ 대학평가의 메타평가 준거 개발 } \\
\text { 기금관리 산하기관에 대한 평가제도 분석 } \\
\text { 책임운영기관 사업성과 메타평가에 관한 연구: 국립중앙극장 중심 } \\
\text { 지방농촌진흥기관에 대한 평가체계 분석 } \\
\text { 우리나라 지방자치단체 평가시스템의 메타평가에 관한 연구 } \\
\text { 정부출연연구기관 평가에 대한 메타평가 모형 설계 및 적용 }\end{array}$ \\
\hline
\end{tabular}

6) 김병철, 2009 , 메타평가론, 한국학술정보, 감사원 평가연구원 재인용 


\section{IV. 개발협력분야에서의 메타평가}

\section{1. 원조기관의 메타평가 특징}

개발협력분야의 메타평가 활용목적은 앞서 설명한 일반적 의미의 메타평가와 같이 다양하다. 그러 나 전반적으로 개발협력 분야의 메타평가는 국내의 행정학에서 쓰이는 개념과 비교하였을 때, 먼저 주요활용 목적측면에서 차이점이 있다. OECD/DAC의 용어집(Glossary)에는 메타평가의 정의를 “평 가결과의 종합(to aggregate findings from a series of evaluations)과 평가품질(to judge its quality and assess the performance of the evaluators)보장 측면에서 활용하는 것으로 정의하고 있으며, 회원국인 오스트리아등 여타 원조기관에서도 동 정의를 준용하고 있다. ${ }^{7)}$ 이는 Chlimsky (1985)가 소개한 “평가결과의 종합(Evaluation Synthesis)" 개념과 일치하며, “평가의 평가(Evaluation of Evaluation)"의 기본개념에 가장 근접해 있다. 즉 메타평가의 다양한 목적과 활용에도 불구하고, 개발협력분야에서는 상위기관의 점검이나, 관리의 목적보다는 기관 대 기관의 대등한 등급으로써 동 료검토(Peer-reviews)성격과 각 원조기관간 평가비교를 통한 상호학습의 목적으로 메타평가가 주로 활용되고 있다는 것을 알 수 있다. 따라서 $\mathrm{OECD} / \mathrm{DAC}$ 에서 권장하는 메타평가는 회원국간의 평가절 차와 일정수준 이상의 평가품질을 보장하고, 원조공여국간 평가를 통한 원조효과성을 비교하고 관리 하기 위한 목적으로 활용되기를 권장하고 있으며8) 이러한 기준에 따라 DAC 동료검토도 이루어지고 있 다. ${ }^{9)}$ Michael Bamberger(외2인)은 특히 개발협력분야 평가를 다룬 저서 "Real World Evaluation" 에서 메타평가를 동료검토(Peer-reviews)와 함께 설명하면서, 평가방법, 자료근거, 결과의 타당성 (Validity)을 평가수행자의 동료(Colleagues)의 입장으로 접근함을 강조하고 있다. ${ }^{10)}$ 세계은행(WB) 이 발간한 개발평가서 “The Road to Results”에서도 메타평가를 평가분야 동일한 전문성을 가진 전 문가의 점검(Review)로 소개하고 있다. ${ }^{11}$

두 번째는 개발협력의 실용적인 측면에서 메타평가를 주로 활용하고 있다는 점이다. 개발원조분야 에서와 같이 평가의 범위가 광대하여 개별평가만으로는 파악하기 힘든 경우, 여러 자금통로로 지원된 프로젝트나 프로그램의 공동평가를 실행하는 경우에 활용한다. $\mathrm{OECD} / \mathrm{DAC}$ 의 공동평가 지침 뿐만아 니라, ${ }^{12)}$ 회원국인 핀란드와 덴마크의 경우는 아래와 같이 두 기관 모두 메타평가의 활용을 공동평가

7) Austrian Development Cooperation, 2009, Guidelines for Project and Programme Evaluations

8) Ministry of Foreign Affairs of Denmark, (2006), Evaluationguidelines

9) DAC, 2008, DAC PEER REVIEW CONTENT GUIDE, OECD,

10) Michael Bamberger, Real World Evaluation Working under budget, Time, Data and Political Constraints, SAGE Publication, p292

11) Linda G. Morra Imas 외1인, 2009, The Road to Results, The World Bank, p203

12) DAC Evalnet, 2006, Managing Joing Evaluations, OECD 
의 유용한 기법으로 소개하고 있다.

"Evaluations focusing on co-financed programmes, the effectiveness of national aid or sectoral goals, or on the evaluation of a multilateral or regional development agency, or on issues that are too sensitive or controversial for one agency alone to tackle, and broad thematic or mata evolutions can often most appropriately be undertaken jointly ${ }^{13)}$ "

특히, 다자기구 평가네트워크 기구인 MOPAN(Multilateral Organization Performance Assesment Network)은 주요 평가기법의 일환으로 메타평가를 활용하고 있다. ${ }^{14)}$ 다자기구나 다자지 원성격의 원조사업에 있어서 메타평가 기법은 평가의 중복성을 방지하고, 요구하는 시간, 비용대비 원 조기관이 현실적으로 선택할 수 있는 효율적인 방법이 될 수 있기 때문에 널리 활용되고 있다. 이는 다양한 국가 및 원조기관, 여러 대상국가 및 자금 경로, 수많은 이해관계자를 등을 포함한 평가범위를 감안하였을 때, 당연한 것일 것이다.

〈참고〉 다자기구성과평가네트워크(MOPAN)

16 개 공여국 간 모임으로 2002년 설립되었으며 매년 3-4개의 다자기구를 선정하여 기관의 조직적효과성 (Organizational Effectiveness)을 평가하고 있다. 평가범위는 대상기관의 전략관리, 사업관리, 파트너쉽관리, 지 식관리 등 네가지이다. 당초 MOPAN은 공여국 및 수원국의 다자사업 담당자들에 대한 인식조사Perception based survey)만을 평가방법론으로 활용하였으나, 최근 다자기구의 정책문서 검토(Document review)를 함께 수행하여 평가결과의 객관성을 높이고자 노력하고 있다. 2010년도에는 $\mathrm{ADB}, \mathrm{WHO}, \mathrm{UNFPA}$, IFA에 대한 평가 를 추진중이며, 회원국으로는 호주, 오스트리아, 벨기에, 캐나다, 덴마크, 핀랜드, 프랑스, 독일, 아일랜드, 네덜 란드, 노르웨이, 스페인, 스웨덴, 스위스, 영국이 활동 중이고, 우리나라는 2008년 가입하였다.

\section{2. 원조기관의 메타평가 사례}

양자기구로써 메타평가를 가장 활발히 활용하는 국가는 스웨덴이며, 국제개발청(Sida)외에도 별도 의 평가청(Swedish Agency for Development Evaluation; SADEV)을 통해 평가의 독립성 확보, 성과중심관리제도 등을 보장하기 위한 활발한 노력의 일환으로 메타평가를 실시 하고 있다. 특히 평가 결과를 바탕으로 지역별/분야별/평가 목적별/기준별 분석을 매년 실시하여 보고서를 발간하고 있으며, 국제기구 및 타 원조기관과의 공동평가(Joint Evaluation)도 메타평가기법을 활용하여 실시하고 있 다. 예를 들어 2010년의 경우 개발과 환경분야의 원조를 통한 저감노력의 성과를 평가하기 위해 파트 너인 $\mathrm{GEF} \mathrm{EO}$ 와 함께 메타평가를 시행하거나, 그 이전 $\mathrm{UNDP}, \mathrm{WFP}$ 기구와 함께 메타평가를 다방면

13) Ministry for foregin affairs of Finland(2007), Evaluation Guidelines, Between Past and Future, p21

14) 대외경제정책연구원, 2010, 다자효과성과 MOPAN(차은주) 발제자료 
으로 실시한 실적을 보유하고 있다. 그리고 무엇보다 이러한 메타평가기법을 통해 축적된 제언사항과 분석을 바탕으로 평가품질(Quality)제고를 위한 제도개선을 활발하게 실시하고 있다. ${ }^{15)}$ 캐나다의 원조 기관(Cida)은 2009년 자국의 다자지원체계를 메타평가 실시하고 이 방법을 다자기구 또는 다자지원성격 의 프로그램 평가 시 활용할 것을 권장하였다. UNEG(United Nations Evalaution Group)이나 $\mathrm{ECG(Evaluation} \mathrm{Cooperation} \mathrm{Group),} \mathrm{MOPAN등이} \mathrm{다루지} \mathrm{못하는} \mathrm{자국의} \mathrm{양자기구지원} \mathrm{전반을} \mathrm{평}$ 가하고자, 2004년에서 2008년 동안 발간된 23개 지원기구의 500개(모집단) 평가보고서를 기준으로 117 개의 보고서를 선택하여, 각 프로젝트 단위의 평가 체계, 과정, 성과관리 등을 전반적으로 점검하고 서면검토위주의 평가를 실시하였다. 다자기구중 $\mathrm{IFAD}$ 나 $\mathrm{AfDB}, \mathrm{UNDP}$ 등은 메타평가를 자주 활용하고 있으며, 양자-다자간, 다자-다자 기구간 협력분야를 넘어 다양하게 실시하고 있다. 최근 인도적지원원 조가 급증하면서, ALNAP(Action Learning Network for Accountability and Performance in Humanitarian Action)과 같은 네트워크에서는 OCHA와 같은 UN국제기구, Red Cross/Crescent와 같이 인도적지원에 참여하는 개발 NGOs등과 함께 메타평가기법을 활용하여 프로그램지원에 대한 성과 관리를 수행하고 있다.

\section{KOICA의 평가분야 시사점}

메타평가의 일반적인 개념과 국 - 내외적인 활용에 대해서 간략히 살펴보았다. 메타평가는 그 활용 과 목적에 따라 여러 가지 장점을 지니고 있다. 평가결과를 종합하여 분석함으로써, 기존의 개별평가 로는 파악할 수 없는 총괄적인 정보와 가치판단에 유용한 자료들을 제공할 수 있다. 또한 평가의 전 수행과정과, 이를 둘러싼 법적, 규범적, 상황적 환경들을 체계적으로 보여줌으로써 평가의 개선방향 을 찾아내고 문제점을 보완할 수 있도록 해준다. 한정된 평가재원과 자원을 효율적으로 이용하게 함 으로써, 재정사업의 경우는 더욱 평가 자체의 타당성을 확보할 수 있다. 무엇보다도, 메타평가를 활 용한 평가의 품질제고와 이를 통한 신뢰성 확보는 가장 강력한 메타평가의 이점일 것이다. 하지만, 정확한 기준 없는 종합적 접근은 자칫 초점 없이 나열식으로 진행될 가능성이 있으며, 무엇보다 평가 자가 또 다시 평가를 받는 것에 대한 저항감도 부딪힐 수 있다. 그리고 메타평가 대상이 되는 기존평 가의 자료질, 형태, 이용 가능성에 따라 메타평가의 품질이 의존될 수 있기 때문에, 이러한 경우는 메 타평가를 통해 의도한 목적을 달성하지 못하는 한계점도 있을 것이다.

15) Sida, 2008, Are Sida Evaluations Good Enough?, An Assessment of 34 Evaluation Reports, 
그렇다면, $\mathrm{KOICA}$ 는 메타평가를 어떻게 활용하고, 접근해야 할 것인가? $\mathrm{KOICA}$ 평가실 ${ }^{16)}$ 은 1998 년 이래, 84 건 156 개사업을 대상으로 사후평가, 주제별 평가, 국별평가 등 다양한 평가를 실시해 왔 다. 하지만 그간 평가결과 및 제언사항을 종합적으로 점검하고 분석하는 메타평가는 이루어지지 않고 있다. 특히 KOICA 평가중기전략(2011년-2013년)의 중요한 제도개선과제의 일환으로 평가의 질 (Quality)제고 방안을 수립하려는 상황 하에서 메타평가를 통해 평가결과를 종합적으로 분석하고, 전 사적으로 분류하여 전략적으로 평가결과를 활용하는 것이 긴요하고 시의적절하다고 판단된다. 다만, 메타평가의 방법과 개념, 그 실익을 정확히 파악하고 실제 적용하기 위해서는 메타평가에 대한 논의 와 관심이 먼저 요구된다.

국내적으로는, $\mathrm{KOICA}$ 의 메타평가기법 도입과 활용가능성은 개발환경을 둘러싼 대외적 요구에 부 합하는 효과적 방법일 수도 있을 것이다. 2009년부터 구성된 국제개발협력위원회 산하 "통합평가위 원회”에서는 한국의 여러 개발이슈와, 현안, 국내 여러 관련기관을 다루고 있기 때문에 주관기관인 국무총리실이 직접적인 통합평가수행을 통한 개발이슈 점검에 업무로드와 어려움이 발생할 수도 있 을 것으로 예상된다. $\mathrm{KOICA}$ 는 분야별 관련부처와 기존 평가를 근거로 메타평가를 실시하고 이러한 과정을 통해 평가통합평가수행을 효율적으로 지원할 수도 있을 것이다. 이러한 경우는 비단 $\mathrm{KOICA}$ 뿐만 아니라, 여러 부처의 평가결과를 점검해야하는 총리실의 경우도 체계적인 메타평가기법을 통해 $\mathrm{ODA}$ 분야 평가현황과 질을 점검할 수 있을 것이다. 다만 메타평가에 대한 관련자들의 공통된 개념과 정의, 필요성이 인식될 때에만 메타평가의 의도한 목적을 달성할 수 있을 것이다.

국제적으로는 KOICA도 메타평가를 통해 다자기구 및 타 원조기관과 적극적으로 협력하고, 평가관 련 정보를 교류하며 학습하는 장으로 이용할 수 있을 것이다. 한국의 전반적인 다자간 원조 지원규모는 2000년대 이후 지속적으로 증가추세에 있으며, ${ }^{17)}$ 외교부 및 $\mathrm{KOICA}$ 를 통한 멀티바이 사업과 같이 다 자기구 성격의 원조형태도 다변화되고 있는 시점이다. 이에 따라 효율적으로 관리하기 위한 평가기법 다양화도 필요한 시점으로 판단된다. 또한 2012년 $\mathrm{OECD} / \mathrm{DAC}$ 의 동료검토를 받기로 예정되어 있는 한국은 국제적 수준의 평가기준을 학습할 시간을 절약하고, 영향력평가(Impact Evaluation)와 같이 최근 중요하게 대두되고 있는 개발평가 이슈 등에 대한 타기관의 경험을 가이드로 활용하기에도 메타 평가의 적절한 활용은 필요할 것으로 생각된다.

16) KOICA 평가실은 사후평가, 국별평가, 정책평가, 분야별 종합평가등을 수행하며, 중간 및 종료평가는 해당 사업부서에서 실시하는 체계이며 동 실적에 중간 및 종료는 포함되지 않았다.

17) 박명지, 2010, 대외무상원조의 다자협력 효과성 제고방안, 한국국제협력단, p77 


\section{VI. 메타평가 활용의 고려사항 및 향후 연구과제 제언}

메타평가는 그 범위와 개념, 활용 등이 다양하게 나타나고 있으며, 그 적용기준 또한 다양하게 나 타났다. 국내에서는 재정사업의 평가기준으로 정착되면서, 행정기관 자체평가의 객관성과 신뢰성에 문제가 있는 경우, 또는 감사(Audit)성격의 메타평가가 더 강조되는 것으로 조사되었다(정부업무평가 기본법 제 17조). ${ }^{18)}$ 이는 메타평가를 정부사업 성과를 점검하고 평가재원을 절약하는 유용한 방법으 로 활용하기 위한 취지일 것이다. 반면 개발협력분야에서의 메타평가는 동등한 기관끼리 유사한 목표 나 목적을 가지고 지원된 프로그램, 프로젝트, 원조사업에 대한 상호 평가정보를 공유하고, 메타평가 를 수행하는 평가자 또한 대등한 동료(Experts)로써 평가품질을 점검(Reviews)하는 것으로 나타났 다. 마치 Scriven의 표현처럼 학회지나 저널에 기고할 때 다른 전문가들에게 연구의 질(Quality)을 점검받고 심사하는 절차와 같은 것이다. 하지만, 메타평가의 기본 전제는 그 대상이 되는 "평가"자체 가 충분히 수행되어야 하고 이를 바탕으로 할 때 여러 메타평가의 방법론을 사용하여 평가의 제도개 선이나 질을 제고할 수 있을 것이다. 또한 국내개발협력분야의 메타평가는 국내의 상위 평가 성격과 는 취지나 목적에 있어서 강조점에 차이가 나는 것으로 조사되었다. 따라서 메타평가를 국제개발협력 분야로 도입하여 추진할 때에는 우선 메타평가를 추진할 만큼 평가의 경험과 실적이 도달했는지에 대 한 점검이 우선 필요할 것이며, 국내기관 중 $\mathrm{KOICA}$ 등이 대표적으로 시도해 볼 수 있을 것이다. 그리 고 $\mathrm{KOICA}$ 또는 개발협력관련 기관에서 메타평가를 추진하고 이를 통한 평가품질 향상을 위해서는, 개발협력분야 특성, 그리고 국내환경과 여건에 맞는 준거틀 및 기준마련 등이 선행되어야 할 것으로 판단된다. 그러한 작업이 선행될 때, 개발협력분야의 특성과 메타평가의 장점들을 부합시켜 효율적으 로 평가의 질을 관리하고, 평가의 신뢰성을 확보할 수 있게 될 것이다.

18) 류영아(2007), 외국의 메타평가 추진실태, 한국정책지식센터, P2 


\section{참고문헌}

\section{1. 국내문헌}

김병철 2009, 메타평가론, 한국학술정보

류영아 2009, 한국행정학보 제43권 제 2호

김태훈 2006 , 문화예술부문 책임운영기관 사업성과 메타평가지표개발 및 실증적 적용, 한국정 책분석평가학회

\section{2. 국외문헌}

Daniel L. Stufflebeam(2001), The Metaevaluation Imperative, American Journal of Evaluation Sida, 2008, Are Sida Evaluations Good Enough?, An Assessment of 34 Evaluation Reports,

DAC, 2010, Quality Standards For Development Evaluation, OECD Austrian Development Cooperation, 2009, Guidelines for Project and Programme Evaluations

Ministry of Foreign Affairs of Denmark(Danida), (2006), Evaluationguidelines

Linda G. Morra Imas 외1인, 2009, The Road to Results, The World Bank, 10.DAC, 2002, G;pssary of Key Terms in Evaluation and Results, OECD 